\title{
Morgagni hernia: Report of two cases and brief review of anatomy and literature
}

\author{
Emilia Krol*1, Michael W. McCormick ${ }^{1}$, Daniel M. Chase ${ }^{2,3}$, Dorothy A. Sparks ${ }^{2,3}$, Gregg L. Bogen ${ }^{2,3}$, Gregory G. \\ Smaroff 2,3 \\ ${ }^{1}$ Department of Surgery, Eastern Virginia Medical School, United States \\ ${ }^{2}$ Department of Surgery, Northside Medical Center, United States \\ ${ }^{3}$ Northeast Ohio Universities College of Medicine, United States
}

Received: February 3, 2018

DOI: $10.5430 /$ css.v4n1p10
Accepted: March 6, 2018

Online Published: March 12, 2018

\begin{abstract}
Morgagni hernias are rare defects which comprise approximately three percent of congenital diaphragmatic hernias. They are often found incidentally but may present with symptoms of bowel obstruction due to viscera entering the hernia sac. Here we present a case series of two Morgagni hernias. The first case is an elderly woman who presented with strangulated transverse colon in the hernia sac, and the other is a young man who complained of vague chest discomfort. These cases exemplify the varied clinical presentation of Morgagni hernias, the importance of being cognizant of their pathology, and their treatment.
\end{abstract}

Key Words: Morgagni hernia, Diaphragmatic hernia, Congenital hernia

\section{INTRODUCTION}

Morgagni hernias are rare retrosternal congenital diaphragmatic defects. Usually found incidentally, they can vary widely in presentation, from bowel obstruction to incidental finding. We submit two cases of Morgagni hernia with different presentations and approaches to treatment.

\section{Case PResentation}

\subsection{Case 1}

An 81-year-old female presented to the emergency department reporting 24 hours of intractable nausea, vomiting, obstipation, and abdominal distention. She denied prior abdominal surgeries or any significant trauma. On exam, her abdomen was distended and diffusely tender without rebound tenderness or guarding, and high-pitched bowel sounds were noted. Laboratory studies showed leukocytosis with left shift.
A plain abdominal radiograph showed distended small bowel and ascending colon with air-fluid levels (see Figure 1). Subsequent barium enema exam revealed a colonic obstruction in the region of the splenic flexure. During this workup, the patient's abdominal exam worsened with the development of peritoneal signs. Given her imaging and clinically worsening exam, she was taken urgently to the operating room for exploratory laparotomy without further imaging.

In the operating room a Morgagni hernia containing omentum and transverse colon was discovered. A segment of distal transverse colon was kinked and necrotic, but there was no frank perforation. The colon proximal to the obstruction was massively distended, and there were areas of patchy ischemia in the cecum. An extended right hemicolectomy including the ischemic area of transverse colon was performed. Unfortunately, the patient's post-operative recovery was hindered

*Correspondence: Emilia Krol; Email: epaszkowiak@gmail.com; Address: Department of Surgery, Eastern Virginia Medical School, United States. 
by respiratory failure, renal failure, and sepsis. She died two weeks after her initial presentation.

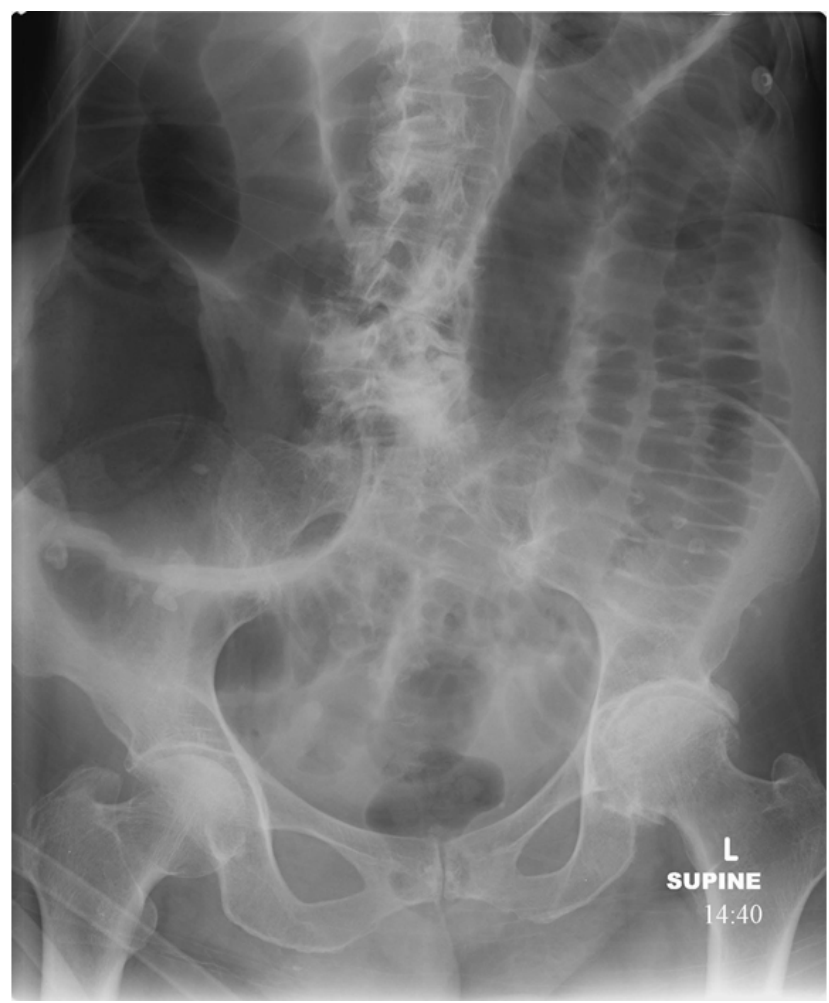

Figure 1. Plain abdominal $x$-ray showing massive cecal distension

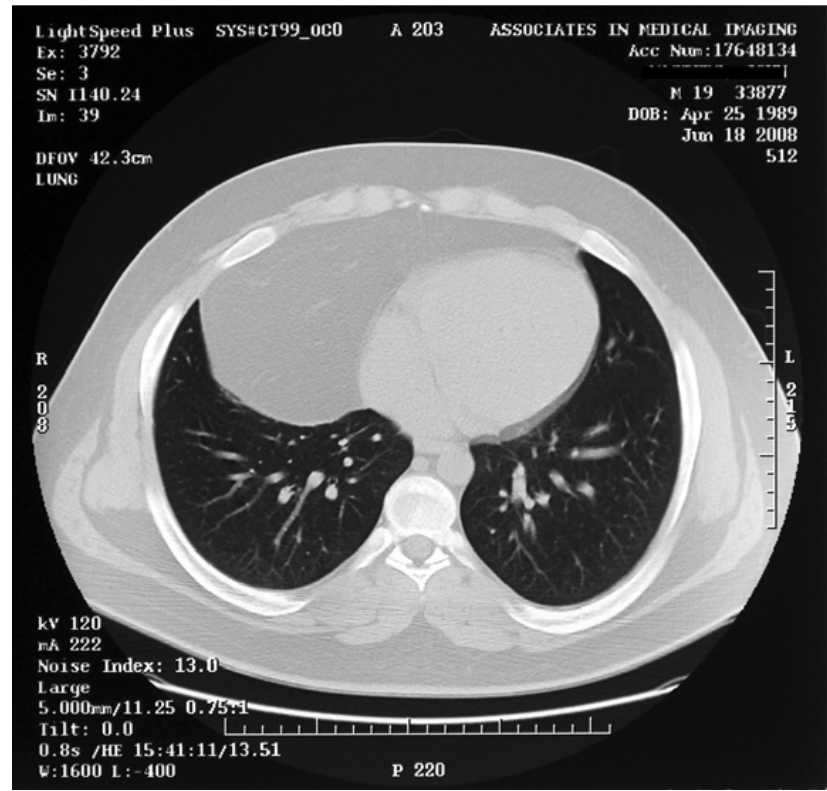

Figure 2. CT chest showing omentum in the Morgagni hernia sac

\subsection{Case 2}

An otherwise healthy 19-year-old male presented to his primary care physician complaining of vague chest discomfort unrelated to activity. Physical exam, history, and laboratory studies were unremarkable. A cardiac evaluation also revealed no pathology. Finally, a non-contrast CT of the chest showed a large Morgagni hernia containing omentum (see Figure 2).

The hernia was repaired electively using a laparoscopic approach. A large retrosternal diaphragmatic hernia containing omentum was found (see Figure 3). After reducing the omentum, there was a large diaphragmatic defect which was closed using a Gore-tex ${ }^{\circledR}$ patch (see Figure 4). The patient did well post-operatively. He was discharged home on post-operative day two with resolution of his chest discomfort.

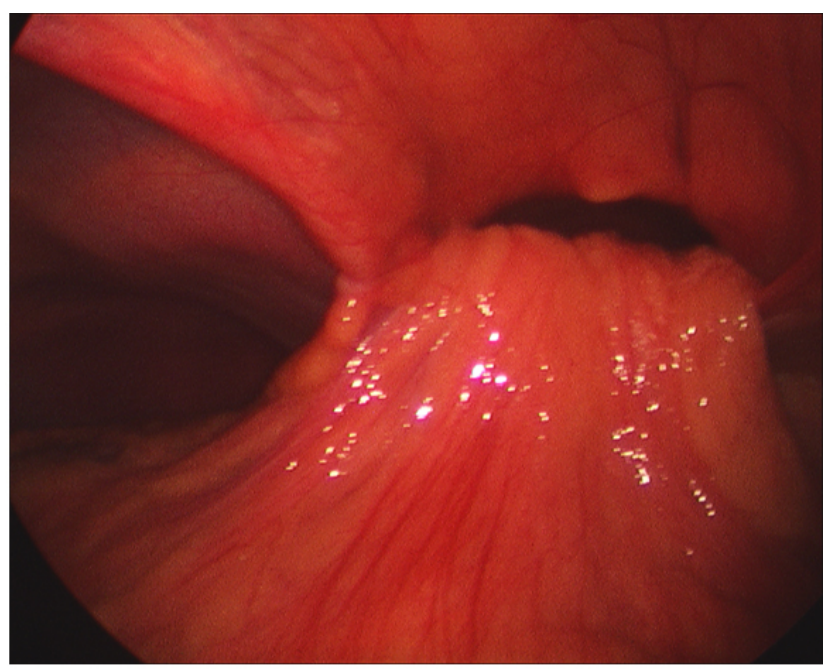

Figure 3. The retrosternal defect containing omentum

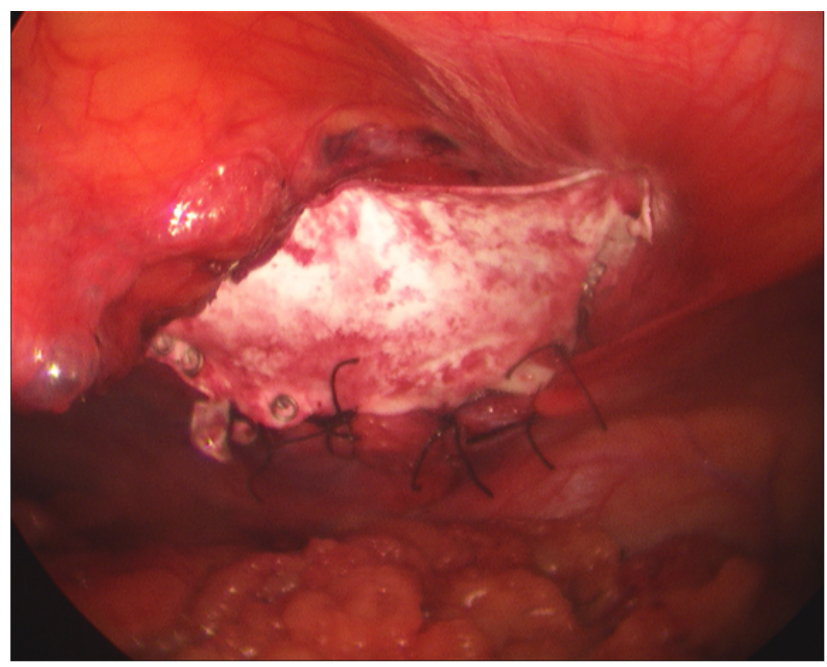

Figure 4. The completed repair with mesh 


\section{Discussion}

Congenital diaphragmatic hernias occur in an estimated 1 in 2,000-5,000 births, ${ }^{[1]}$ and approximately three percent of these are Morgagni hernias. ${ }^{[2]}$ The diaphragm is derived from the septum transversum ventrally, the pleuroperitoneal membrane and body wall laterally, and mesoesophagus mediodorsally. Failure of fusion of these structures in the retroxiphoid region results in a Morgagni hernia. ${ }^{[3]}$ Specifically, it arises from a septum transversum defect due to failure of closure of the pars sternalis and the seventh costochondral arch, known as Larrey's space. ${ }^{[4]}$ Diaphragmatic hernia through this space was first described by the Italian anatomist Giovanni Morgagni in $1769 .^{[1]}$

The Morgagni hernia appears as an oval shaped defect on a transverse axis. Its front edges are combined to the osteocartilaginous thoracic wall, and its back edges are joined to the muscular edge of the diaphragm. ${ }^{[5]}$ The sac of a Morgagni hernia may contain omentum, transverse colon, and, less commonly, stomach and liver. ${ }^{[4]}$ Ninety percent of Morgagni hernias are right sided, two percent left sided, and eight percent bilateral. ${ }^{[1]}$ Morgagni hernias are rarer on the left side because the pericardial sac forms a barrier on the sternocostal trigon. ${ }^{[6]}$

Fifty to seventy percent of patients diagnosed with Morgagni hernias are asymptomatic, and their hernias are found during workup of other problems. ${ }^{[4,7]}$ Pulmonary complaints are the most common presenting symptoms. ${ }^{[8]}$ Acute symptoms may be due to bowel obstruction, but the incidence of this is very low. ${ }^{[2,3]}$ The overwhelming majority of Morgagni hernias are diagnosed in children, though approximately five percent are diagnosed in adults. ${ }^{[1]}$ The most common adult presentation is in middle-aged, overweight women. ${ }^{[4]}$ Trauma, severe exertion, and obesity may cause enlargement of previously clinically insignificant hernias in adults, leading to symptoms and late presentation. ${ }^{[1]}$

In children, Morgagni hernias are frequently associated with other congenital anomalies. They may present with severe respiratory distress, recurrent chest infections, or intermittent gastrointestinal symptoms. ${ }^{[9]}$ The incidence of male and female cases in children is roughly equal. ${ }^{[10]}$

Computed Tomography is considered the gold standard for diagnosing and evaluating Morgagni hernias and other diaphragmatic defects. ${ }^{[4,11]}$ Bowel and omentum can easily be seen on a non-contrast scan. ${ }^{[6]}$ Endoscopy is generally not helpful in diagnosis. ${ }^{[7]}$ When patients present with complica- tions such as incarceration, bowel obstruction, strangulation, and gastric volvulus, timely repair of Morgagni hernias is mandatory. ${ }^{[7,12]}$ The hernia is closed along its transverse axis by suturing the edge of the diaphragm to the retrosternal and retrocostal peritoneum and periosteum. ${ }^{[3,5]}$ About half of the reported hernias are repaired with mesh, and half are repaired primarily. ${ }^{[12]}$ Mesh has been particularly advocated in cases of large defects or muscle weakness. ${ }^{[4,11]}$

Morgagni hernias may be repaired via a thoracic or abdominal approach, but bowel obstruction mandates an abdominal approach. ${ }^{[1,13]}$ Large right-sided defects are also frequently repaired with combined transthoracic and transabdominal approaches ${ }^{[13,14]}$ The first laparoscopic repair of a Morgagni hernia was reported in $1992 .{ }^{[3]}$ Laparoscopy reduces postoperative pain, ileus, and hospitalization time and leads to quicker recovery of activity. ${ }^{[5,12]}$ There is currently no consensus regarding the management of the hernia sac in laparoscopic repairs. Some advocate resecting it, and others recommend leaving it in place to prevent massive pneumomediastinum and resulting respiratory compromise. ${ }^{[12]}$ Not excising the sac is technically easier with minimal risk of complications appears to be the safer approach. ${ }^{[8,10,13,15]}$ The reported relapse and mortality rates for repair of Morgagni hernias are extremely low. ${ }^{[5]}$ Although the thoracoscopic approach to repairing Bochdalek hernias has gained traction, Morgagni hernia repair remains primarily in the realm of upper GI laparoscopic surgeons at this time. ${ }^{[16]}$ Limited series advocate thoracoscopic approach in Morgagni hernia patients with severe intrathoracic adhesions due to chronic bowel herniation. ${ }^{[17]}$ Currently there is no consensus on the optimal approach to repairing Morgagni hernias, and each case should be considered on an individual basis.

\section{Conclusions}

Morgagni hernias are rare retrosternal congenital diaphragmatic defects. Usually found incidentally, they can present with bowel obstruction or ischemia. Most are found in children, but a minority are found in adults. Computed tomography is the method of choice for diagnosis. The hernia is repaired by suturing the edge of the diaphragm to the retrosternal and retrocostal peritoneum and periosteum. The laparoscopic approach to Morgagni hernia repair has been shown to be safe and beneficial.

\section{CONFlicts OF InTEREST Disclosure}

The authors declare they have no conflicts of interest. 


\section{REFERENCES}

[1] Barut I, Tarhan OR, Cerci C, et al. Intestinal obstruction caused by a strangulated morgagni hernia in an adult patient. Journal of Thoracic Imaging. 2005; 20: 220-222. PMid: 16077338. https: //doi.org/10.1097/01.rti.0000154078.59689.36

[2] Sakalkale RP, Sankhe M, Nagral S, et al. Obstructed morgagni's hernia. Journal of Postgraduate Medicine. 1991; 37: 229-230.

[3] Kuster GGR, Kline LE, Garzo G. Diaphragmatic hernia through the foramen of morgagni: laparoscopic repair case report. Journal of Laparoendoscopic Surgery. 1992; 2: 93-100. PMid: 1534498. https://doi.org/10.1089/lps.1992.2.93

[4] Eren S, Gumus H, Okur A. A rare cause of intestinal obstruction in the adult: morgagni's hernia. Hernia. 2003; 7: 97-99. PMid: 12820034. https ://doi.org/10.1007/s10029-002-0099-4

[5] Carcoforo P, DiMarco L, Schettino AM, et al. Intestinal occlusion secondary to morgagni-larrey's herniation in an adult: case report and analysis of the literature. Ann Ital Chir. 1998; 69: 97-100. PMid: 11995044

[6] Kurkcuoglu IC, Eroglu A, Karaoglanoglu N, et al. Diagnosis and treatment of morgagni hernia: report of three cases. Surgery Today. 2003; 33: 525-528. PMid: 14506998.

[7] Dodis BD, Bennett MW. Gastroduodenal obstruction from morgagni hernia in an elderly patient. Medscape General Medicine. 2005; 7 : 70 .

[8] Horton JD, Hofmann LJ, Hetz SP. Presentation and management of Morgagni hernias in adults: a review of 298 cases. Surg Endosc. 2008; 22(6): 1413-20. PMid: 18347869. https ://doi.org/10.1 007/s00464-008-9754-x

[9] Vaos G, Skondras C. Colonic necrosis because of strangulated recurrent morgagni's hernia in a child with down's syndrome. Jour- nal of Pediatric Surgery. 2006; 41: 589-591. PMid: 16516643 https://doi.org/10.1016/j.jpedsurg.2005.11.063

[10] Kimmelstiel FM, Holgersen LO, Hilfer C. Retrosternal (morgagni) hernia with small bowel obstruction secondary to a richter's incarceration. Journal of Pediatric Surgery. 1987; 22: 998-1000. https : //doi.org/10.1016/S0022-3468(87)80494-3

[11] Testini M, Girardi A, Isernia RM, et al. Emergency surgery due to diaphragmatic hernia: case series and review. World Journal of Emergency Surgery. 2017; 12: 23. https ://doi.org/10.1186/s130 17-017-0134-5

[12] White DC, McMahon R, Wright T, et al. Laparoscopic repair of a morgagni hernia presenting with syncope in an 85 year old woman: case report and update of the literature. Journal of Laparoendoscopic and Advanced Surgical Techniques. 2002; 12: 161-165. PMid: 12184900 https://doi.org/10.1089/10926420260188047

[13] Kesieme EB, Kesieme CN. Congenital diaphragmatic hernia: review of current concept in surgical management. ISRN Surg. 2011; 2011: 974041.

[14] Marinceu D, Loubani M, O'grady H. Late presentation of a large Morgagni hernia in an adult. BMJ Case Rep. 2014; 2014.

[15] Pironi D, Palazzini G, Arcieri S, et al. Laparoscopic diagnosis and treatment of diaphragmatic Morgagni hernia. Case report and review of the literature. Ann Ital Chir. 2008; 79(1): 29-36. PMid: 18572736.

[16] Amer K. Thoracoscopic approach to congenital diaphragmatic hernias in adults: Southampton approach and review of the literature. J Vis Surg. 2017; 3: 176. PMid: 29302452. https ://doi.org/10.2 1037/jovs. 2017.10.05

[17] Nakashima S, Watanabe A, Hashimoto M, et al. Advantages of videoassisted thoracoscopic surgery for adult congenital hernia with severe adhesion: report of two cases. Ann Thorac Cardiovasc Surg. 2011; 17: 185-9. https://doi.org/10.5761/atcs.cr.09.01528 